\title{
As contribuições da tese de William Paton (1922): Accounting Theory
}

\author{
Vanuza da Silva Figueiredo ${ }^{1}$
}

Recibido: 27 de maio de 2019

Aprovado: 20 de junho de 2019

Figueiredo, V. (2019). As contribuições da tese de William Paton (1922): Accounting Theory. Revista Activos, 17(2), 127-158. DoI: https://doi. org/10.15332/25005278/5735

\section{Clasificación JEL: M49}

\section{Resumo}

Este trabalho tem o objetivo de identificar as principais contribuições sobre o fator de impacto da tese de William Andrew Paton (1922). Uma tese

1 Doutoranda em Ciências Contábeis na Universidade de Brasília. Mestre em Ciências Contábeis pela Universidade do Estado do Rio de Janeiro (2013). Especialista em Gestão Pública Municipal pela Universidade Federal Fluminense (UfF, 2015) e graduada em Ciências Contábeis pela UfF (2005). Participante do Programa de Voluntariado da Classe Contábil do Conselho Regional de Contabilidade. Professora assistente da UfF. Tutora no curso de pós-graduação lato sensu Gestão Pública Municipal da Uff. Tem experiência na área de Administração, com ênfase em Ciências Contábeis, com atuação principalmente nos temas: contabilidade pública, administração pública e auditoria governamental. E-mail: vanuzafigueiredo@hotmail.com ORCID: https://orcid.org/0000-0002-9050-3706 
desenvolvida há quase um século, mas que permanece atual e relevante fonte de dados para o entendimento da teoria da Contabilidade ao longo dos anos. Mesmo de forma embrionária, o trabalho de Paton traz uma contribuição para a ideia de mensuração e uma introdução ao conceito de "custo corrente". Trata-se de uma pesquisa exploratória, que utilizou o método empregado por Oppenheim e Renn (1978) para a análise de tipologias de citações, por meio do qual pudemos observar que a maioria das citações foi classificada na tipologia c. Os resultados também evidenciaram, por um lado, que as principais contribuições da obra de Paton (1922) consistem no custo corrente, no goodwill e nos postulados. Por outro, muitos pesquisadores, em vez de explorarem a obra de Paton (1922), limitam-se a fazer citações de citações (introduzidas pela preposição latina apud) de livros de teoria da Contabilidade que citam essa obra.

Palavras-chave: Paton; teoria da Contabilidade; história da Contabilidade; citação; apud.

\section{Los aportes de la tesis de William Paton (1922): Accounting Theory}

\section{Resumen}

El propósito del trabajo es identificar los principales aportes sobre el factor de impacto de la tesis de William Andrew Paton (1922). Una tesis desarrollada desde hace un siglo, pero que permanece actual y relevante fuente de datos para entender la teoría de la Contabilidad a lo largo de los años. Aun de forma embrionaria, el trabajo de Paton trae un aporte para la idea de mensuración y una introducción al concepto de "costo corriente". Se trata de una investigación exploratoria, que utilizó el método empleado por Oppenheim y Renn (1978) para analizar tipologías de citas, por medio del ello hemos podido observar que la mayoría de las citas se clasificó en la tipología C. Los resultados también dan cuenta, por un lado, que los principales aportes 
de la obra de Paton (1922) consisten en el costo corriente, el goodwill y los postulados. Por otro, muchos investigadores, en vez de explorar la obra de Paton (1922), se limitan a hacer citas de citas (introducidas por la preposición latina apud) de libros de teoría de la Contabilidad que citan esta obra.

Palabras clave: Paton, teoría de la Contabilidad, historia de la Contabilidad, cita, apud.

\title{
The Contributions of William Paton's Thesis (1922) Accounting Theory
}

\begin{abstract}
The aim of this paper is to identify the main contributions to the impact factor of William Andrew Paton's thesis (1922). This thesis was developed a century ago but remains as a current and relevant data source to understand the accounting theory over the years. Even in an embryonic form, Paton's work brings a contribution to the idea of measurement and an introduction to the concept of "current cost." It is an exploratory research, which used the method employed by Oppenheim and Renn (1978) to analyze citation typologies, through which we have been able to observe that most of the citations were classified in the $\mathrm{C}$ typology. Results also show, on the one hand, that the main contributions of Paton's work (1922) are current cost, goodwill, and postulates. On the other hand, instead of exploring Paton's work (1922), many researchers limit themselves to making citations (introduced by the Latin preposition apud) from accounting books that cite this work.
\end{abstract}

Keywords: Paton, accounting theory, accounting history, citation, apud. 


\section{Introdução}

Em qualquer parte do mundo, independentemente da escola de Contabilidade utilizada, o estudo da história das Ciências Contábeis é um assunto que precisa ser discutido e difundido com amplidão. Para o avanço do campo, é preciso um abrangente entendimento das origens das abordagens e dos conceitos empregados. Dessa forma, é essencial trazer, para as pesquisas atuais, uma fundamentação dos conceitos oriundos de legados dos pesquisadores pioneiros.

É necessário ressaltar que as pesquisas que abordam a história da Contabilidade são de suma importância para a compreensão da evolução do conhecimento. Os conceitos difundidos na Contabilidade são frutos de diversas contribuições históricas, o que torna indispensável, portanto, identificarmos os principais autores que desenvolveram pesquisas seminais sobre a teoria da Contabilidade.

Este artigo tem como objetivo discutir a tese de Paton (1922) e suas principais contribuições para a teoria da Contabilidade. Esse tipo de pesquisa se justifica pela constante necessidade de buscar respostas no passado para fundamentar e compreender fenômenos existentes nos dias atuais.

A divisão do artigo é apresentada a seguir. Na segunda seção, reviso a literatura sobre a tese de Paton (1922); na terceira seção, apresento a metodologia empregada neste estudo. Em seguida, trago a análise dos resultados e as conclusões da pesquisa.

\section{Referencial teórico}

\section{A história da Contabilidade}

Dentro de um aspecto arqueológico, a Contabilidade manifestou-se há quase dez séculos, portanto muito antes do próprio homem ter desenvolvido o 
espírito de civilidade. Assim como o homem progrediu, a Contabilidade, como uma ferramenta indispensável para o progresso da humanidade, perseguiu esse progresso. $O$ epítome do enredo evolutivo da Contabilidade leva ao desfecho de que, igual a qualquer ramo de conhecimento intimamente relacionado com o contexto social, a história do pensamento contábil é produto do meio social em que o usuário está inserido, tanto em termos de espaço como de tempo. Em sítios arqueológicos, foram encontrados materiais utilizados por civilizações pré-históricas que caracterizam um sistema contábil utilizado entre 8.000 e 3.000 a. C., constituído de pequenas fichas de barro (Santos, Schmidt, Pinheiro e Nunes, 2006).

Quanto à história da Contabilidade, as obras de Paton estão enquadradas na Escola Norte-Americana, como observado no quadro a seguir.

Quadro 1. Escolas de pensamento contábil

\begin{tabular}{l|l|l|l|l}
\hline $\begin{array}{c}\text { Escolas de } \\
\text { pensamento } \\
\text { contábil }\end{array}$ & Período & $\begin{array}{l}\text { Principais } \\
\text { autores }\end{array}$ & \multicolumn{1}{|c}{ Características } & Objetivo \\
\hline $\begin{array}{l}\text { Escola } \\
\text { Contista }\end{array}$ & Século & $\begin{array}{l}\text { Cotrugli, } \\
\text { Leonardo } \\
\text { Fibonacci, } \\
\text { Frei Luca } \\
\text { Pacioli }\end{array}$ & $\begin{array}{l}\text { Preocupação em } \\
\text { descrever e apresentar } \\
\text { exemplos de como } \\
\text { registrar transações } \\
\text { em livros contábeis por } \\
\text { meio de partidas simples } \\
\text { ou dobradas. Trabalho } \\
\text { centrado em contas. }\end{array}$ & $\begin{array}{l}\text { Registro das } \\
\text { contas a pagar e } \\
\text { a receber. }\end{array}$ \\
\hline $\begin{array}{l}\text { Escola } \\
\text { Administrativa } \\
\text { ou Lombarda }\end{array}$ & $\begin{array}{l}\text { Século } \\
\text { XIx }\end{array}$ & $\begin{array}{l}\text { Francesco } \\
\text { Villa e } \\
\text { Antonio } \\
\text { Tonzig }\end{array}$ & $\begin{array}{l}\text { Inclusão na } \\
\text { Contabilidade de fatores } \\
\text { econômicos de produção } \\
\text { e de consumo. } \\
\text { Estudo da administração } \\
\text { das entidades; } \\
\text { aplicação de princípios } \\
\text { econômicos ao campo } \\
\text { da Contabilidade. } \\
\text { A Contabilidade como } \\
\text { fonte de informação } \\
\text { gerencial. }\end{array}$ & $\begin{array}{l}\text { Conexão entre } \\
\text { os elementos } \\
\text { contábeis e } \\
\text { os elementos } \\
\text { econômico- } \\
\text { administrativos. }\end{array}$ \\
\hline
\end{tabular}




\begin{tabular}{|c|c|c|c|c|}
\hline $\begin{array}{c}\text { Escolas de } \\
\text { pensamento } \\
\text { contábil }\end{array}$ & Período & $\begin{array}{c}\text { Principais } \\
\text { autores }\end{array}$ & Características & Objetivo \\
\hline $\begin{array}{l}\text { Escola } \\
\text { Personalista }\end{array}$ & $\begin{array}{l}\text { Século } \\
\text { XIX }\end{array}$ & $\begin{array}{l}\text { Francesco } \\
\text { Marchi, } \\
\text { Giuseppe } \\
\text { Cerboni e } \\
\text { Giovanni } \\
\text { Rossi }\end{array}$ & $\begin{array}{l}\text { Interesse pelo aspecto } \\
\text { jurídico das relações } \\
\text { entre o proprietário e a } \\
\text { entidade. } \\
\text { Uso da teoria } \\
\text { logismográfica. } \\
\text { Teoria da personificação } \\
\text { das contas. }\end{array}$ & $\begin{array}{l}\text { As contas } \\
\text { deveriam ser } \\
\text { abertas em } \\
\text { nome de pessoas } \\
\text { verdadeiras, } \\
\text { físicas ou } \\
\text { jurídicas, e o } \\
\text { dever e o haver } \\
\text { representavam } \\
\text { débitos e } \\
\text { créditos das } \\
\text { pessoas titulares } \\
\text { dessas contas. }\end{array}$ \\
\hline $\begin{array}{l}\text { Escola } \\
\text { Veneziana ou } \\
\text { Controlista }\end{array}$ & $\begin{array}{l}\text { Século } \\
\text { XIX }\end{array}$ & $\begin{array}{l}\text { Fábio } \\
\text { Besta, } \\
\text { Vittorio } \\
\text { Alfieri, } \\
\text { Carlo } \\
\text { Ghidiglia, } \\
\text { Pietro } \\
\text { Rigobon } \\
\text { e Pietro } \\
\text { D’Alvise }\end{array}$ & $\begin{array}{l}\text { Distinção entre } \\
\text { o conceito de } \\
\text { "administração geral" } \\
\text { e "administração } \\
\text { econômica". } \\
\text { Dedicação de muita } \\
\text { atenção ao processo de } \\
\text { continuidade da gestão. } \\
\text { O patrimônio } \\
\text { representado pela } \\
\text { soma de valores } \\
\text { ativos e passivos. } \\
\text { A administração } \\
\text { econômica compreende: } \\
\text { a gestão, a direção e a } \\
\text { verificação/controle. } \\
\text { Preocupação com } \\
\text { estudos históricos da } \\
\text { Contabilidade. }\end{array}$ & $\begin{array}{l}\text { A Contabilidade } \\
\text { como ciência } \\
\text { do controle } \\
\text { econômico. }\end{array}$ \\
\hline
\end{tabular}




\begin{tabular}{|c|c|c|c|c|}
\hline $\begin{array}{c}\text { Escolas de } \\
\text { pensamento } \\
\text { contábil }\end{array}$ & Período & $\begin{array}{c}\text { Principais } \\
\text { autores }\end{array}$ & Características & Objetivo \\
\hline $\begin{array}{l}\text { Escola Norte- } \\
\text { Americana }\end{array}$ & $\begin{array}{l}\text { Século } \\
\mathrm{xx}\end{array}$ & $\begin{array}{l}\text { Charles } \\
\text { Ezra } \\
\text { Sprague, } \\
\text { Henry } \\
\text { Rand } \\
\text { Hatfield, } \\
\text { William } \\
\text { Andrew } \\
\text { Paton, } \\
\text { Ananias } \\
\text { Charles } \\
\text { Littleton, } \\
\text { Carman } \\
\text { George } \\
\text { Blough, } \\
\text { Maurice } \\
\text { Moonitz, } \\
\text { Raymond } \\
\text { Chambers, } \\
\text { Richard } \\
\text { Mattessich, } \\
\text { Lawrence } \\
\text { Robert } \\
\text { Dicksee, } \\
\text { Kenneth } \\
\text { Most, } \\
\text { Kenneth } \\
\text { Forsythe } \\
\text { MacNeal }\end{array}$ & $\begin{array}{l}\text { Grande parte de suas } \\
\text { construções teóricas teve } \\
\text { origem em entidades } \\
\text { ligadas a profissionais da } \\
\text { área contábil. } \\
\text { Preocupação com } \\
\text { a qualidade das } \\
\text { informações contidas } \\
\text { nas demonstrações } \\
\text { contábeis, especialmente } \\
\text { no que tange a } \\
\text { informações para } \\
\text { investidores no mercado } \\
\text { de ações. } \\
\text { A padronização } \\
\text { financeira tornou-se um } \\
\text { dos mais controvertidos } \\
\text { aspectos do } \\
\text { doutrinamento contábil } \\
\text { norte-americano. } \\
\text { Padronização do } \\
\text { trabalho de auditoria. } \\
\text { Para Hatfield, as teorias } \\
\text { deveriam derivar, } \\
\text { indubitavelmente, da } \\
\text { prática e da experiência, } \\
\text { de preferência de } \\
\text { premissas abstratas. }\end{array}$ & $\begin{array}{l}\text { Progresso } \\
\text { doutrinário da } \\
\text { Contabilidade } \\
\text { financeira e } \\
\text { dos relatórios } \\
\text { contábeis } \\
\text { e enorme } \\
\text { expansão da } \\
\text { Contabilidade } \\
\text { gerencial, } \\
\text { especialmente } \\
\text { no que tange à } \\
\text { qualidade da } \\
\text { informação } \\
\text { interna para } \\
\text { a tomada de } \\
\text { decisão. }\end{array}$ \\
\hline
\end{tabular}

Fonte: elaborado a partir da obra de Schmidt (2000). 


\section{William Andrew Paton}

William Andrew Paton possui um extenso currículo. Filho de professores, Paton (após a graduação em Economia) iniciou sua carreira acadêmica na Universidade de Michigan em 1914; trabalhou como professor assistente na Universidade de Minnesota em 1916 e 1917; retornou à Universidade de Michigan, onde foi professor de Contabilidade e Economia em 1921. Levou seus conhecimentos para a Universidade da Califórnia, Berkeley (19371938), para a Universidade de Harvard (1939-1940), para a Universidade de Chicago (1959-1960) e para a Universidade de Kentucky (1968-1969), nesta última universidade lecionou como professor visitante e exerceu consultoria como contador. Foi premiado com o título de Educador Contábil do Século pelo American Institute of Certified Public Accountants. Paton deixou um legado: escreveu diversos livros e artigos. Ele era o editor do Accountants Handbook, um dos fundadores da American Accounting Association e, em 1926, começou a Accounting Review, o mais antigo periódico acadêmico em Contabilidade.

Em 1922, Paton concluiu sua tese intitulada Accounting theory with special reference to the corporate enterprise, que será o tema deste artigo. Esse estudo trouxe diversas contribuições para a teoria da Contabilidade, pois enfoca temas ainda atuais e constantemente debatidos na área. Cabe destacar que Paton escreveu essa tese ainda muito jovem (com aproximadamente 30 anos de idade), logo após a Primeira Guerra Mundial.

O Accounting Hall of Fame foi criado em 1950 na Universidade Estadual de Ohio com o objetivo de honrar e reconhecer serviços e contribuições diferenciados para o progresso da Contabilidade em qualquer um de seus diversos campos. Eram notáveis as contribuições de Paton para a pesquisa e para a literatura contábil, além do serviço significativo para as organizações profissionais de Contabilidade e desenvolvia um amplo reconhecimento como autoridade na área, avanço do ensino contábil e serviço público. No mesmo ano no primeiro Accounting Hall of Fame, William Andrew Paton, George Oliver May e Robert Hiester Montgomery foram premiados. 
Em diversos momentos da tese, que se tornou um livro, Paton salientava sua preocupação em ensinar aos contadores da maneira mais didática e ilustrativa possível, fazendo questão de alertar constantemente o contador sobre a importância da prática aliada à teoria. O livro, portanto, teve como objetivo apresentar uma reafirmação da teoria da Contabilidade, condizente com as condições e necessidades de empreendimento de grandes corporações, bem como aplicável a formas mais simples e mais primitivas de organização.

Paton, em vários momentos, mostrou-se preocupado em alertar o contador sobre diversos pontos importantes da Contabilidade; como, por exemplo, o uso das expressões: "o contador deve ter em mente", "o contador poderia", "é desejável, no entanto, sugerir que o contador". Ele teve, portanto, o zelo de trazer contribuições que auxiliassem o contador no exercício da profissão, sempre de forma acessível e com profusão de ensinamentos.

Ao contrário das publicações atuais, naquela época, eles não apresentavam nas referências as obras citadas ao longo do trabalho. Segundo Santos et al. (2006), os livros Modern Accounting: Its Principles and some of its problems, de autoria de Hatfield, e The philosophy of accounts, de Sprague, estimularam o interesse de Paton pela Contabilidade e representaram o ponto de partida para o desenvolvimento de seu trabalho de doutoramento. Logo no prefácio, Paton (1922) traz a afirmação de que a teoria da Contabilidade poderia ser descrita como "Contabilidade proprietária", a qual é a opinião de escritores como Sprague, Hatfield e outros.

Williams e Lawrence (2018) desenvolverem um livro sobre o estudo do pensamento contábil realizado por Paton e apresentaram o autor como um profissional renomado e reconhecido mundialmente como autoridade em Contabilidade teórica e pioneiro no desenvolvimento da educação contábil. Para os autores, seus pensamentos, sua história, suas crenças e suas realizações devem ser preservados para futuros contadores, pois ele ganhou uma reputação merecida como orador eloquente, defensor e forte crítico da Contabilidade, além de ser considerado um dos grandes contadores do século XX. 
Houve, na década de 1920, grande salto de qualidade com os trabalhos de Paton (1922) e de outros grandes nomes da Contabilidade, o que se seguiu até a década de 1980. Assim, houve uma enorme quantidade de trabalhos empíricos desde então, o que deixou os grandes normativistas atônitos ao traçarem as tendências (Iudícibus e Martins, 2015).

A pesquisa histórica na Contabilidade é importante para acompanhar a evolução e explicar conceitos atuais oriundos de contribuições passadas, pois o reconhecimento das etapas vividas pela ciência é essencial para uma maior compreensão de definições complexas. Assim, esta pesquisa visa identificar as principais contribuições da tese de Paton (1922).

\section{Principais contribuições da tese de Paton (1922): Accounting Theory}

As principais contribuições da obra de Paton (1922) consistem no custo corrente, no goodwill e nos postulados. Ele aborda, em muitos casos, a adoção do custo corrente como base para avaliação. Mais uma vez, deve ficar claro que o reconhecimento do reforço, que simplesmente mede a mudança de custo corrente efetivo, não envolveria, em geral, a antecipação de renda e a acumulação da margem normal de renda. É claro que os preços de venda seguem os custos de substituição.

A esse respeito, Paton $(1918,1922)$ e Schmidt (1921) partiram da ênfase colocada sobre custos de reposição ou valores de mercado; logo em seguida, esse modelo de custo foi defendido por Sweeney (1932), MacNeal (1939) e Zeff (2016).

Paton, no capítulo XIII, também teve uma discussão ampla acerca do goodwill, embora não tenha sido pioneiro ao tratar do tema. Uma das pesquisas mais antigas sobre o goodwill está presente no trabalho de Harris (1884), que o definiu como o valor monetário além dos ativos reais de interesse (como book debits, stock-in-trade, machinery etc.) 
e que pode ser realizado em casos de morte, dissolução, aposentadoria ou liquidação.

Cooper (2007) discutiu os princípios e políticas contábeis a respeito do goodwill entre 1880 e 1921, identificando em sua análise que havia várias áreas de concordância no que diz respeito à sua contabilização. Estas incluem a natureza e definição do goodwill, o seu estatuto como ativo da Contabilidade, a sua inseparabilidade do negócio como um todo e a sua capacidade de ser avaliado separadamente, e as circunstâncias do seu reconhecimento nas contas. No entanto, foi identificada uma diferença significativa na opinião relativa ao tratamento do goodwill, adquirido após o seu registro nas contas. Houve consenso de que a baixa imediata de tal boa vontade para as reservas seria o tratamento contábil mais adequado para as empresas não constituídas em sociedade (empresa individual e coletiva).

Em várias áreas, vê-se o impacto do pensamento de Paton, a saber: ágio, estoque de tesouraria e contabilidade de ativos e instalações etc. Paton criou esses conceitos? Em muitos casos, a resposta é "não". No entanto, o ponto crítico a se ter em mente é que ele os trouxe à vanguarda, onde eles poderiam ser examinados e discutidos. Ele pode unir com maestria a teoria e a prática (Williams e Lawrence, 2018).

Antes de Paton, outros autores já desenvolviam os conceitos utilizados atualmente, o que reafirma que o conceito de "goodwill" não é uma contribuição exclusiva dele.

Hendriksen e van Breda (2010) destacam que raramente, até então, um autor captou tão bem ou sucintamente as limitações da Contabilidade pelo custo histórico. Tal como Pacioli, os comentários secos de Paton podem ser lidos com tanto frescor hoje em dia quanto na época em que foram redigidos.

Alguns dos escritores na teoria, notavelmente Sprague e Hatfield, não satisfeitos apenas em descrever a prática, abordaram com seriedade a exposição da teoria pura; mas os escritores de livros didáticos, em sua maior 
parte, muito naturalmente se preocuparam com a prática, apenas com um aceno ocasional em direção à teoria, com a qual pareciam reforçar a prática (Williams e Lawrence, 2018).

Esses autores destacam que a busca por princípios contábeis antes dos valores mobiliários - a maioria da literatura contábil não se afastou da prática - e as prescrições eram geralmente baseadas em racionalizações da prática. Até propostas de Contabilidade de nível de preço de Sweeney dos anos 1920 foram baseadas na prática.

Soares e Vicente (2014) identificaram, nas propostas de ementa para a disciplina Teoria da Contabilidade, de diversos autores, um alto grau de similaridade, mesmo em nível de mestrado. Entre os autores, observam-se alguns pontos comuns: indicação de tópicos sobre a história e evolução da Contabilidade; objeto e objetivos da Contabilidade e das demonstrações contábeis; mensuração e reconhecimento de ativos e passivos; receitas e despesas; perdas e ganhos; princípios, postulados e convenções; normas internacionais e brasileiras de Contabilidade, e evidenciação (disclosure).

A história da Contabilidade possui diversos pioneiros, por isso há necessidade de se compreender e se valorizar as contribuições dessas personagens ao longo dos séculos.

Diversos pontos são apresentados na obra de Paton, porém poucos são os autores que exploram essa obra para analisar a sua influência nas discussões atuais sobre a teoria da Contabilidade. Ao longo da leitura do texto de Paton, identificamos que ele buscou, na prática, a construção desse "marco conceitual".

\section{Os postulados}

As maiores contribuições da tese de Paton são os postulados. Um grande número de pesquisadores da área contábil recorre ao livro de Hendriksen 
e van Breda para extrair tais definições, em vez de buscar, nas fontes primárias, o embasamento de seus trabalhos.

A tese de Paton trouxe uma reafirmação da teoria da Contabilidade consistente com as condições e necessidades das grandes corporações. No capítulo xx, ele discute suposições básicas ou "postulados" que sustentam a estrutura da Contabilidade moderna (Zeff, 1999a). Nos escritos de Paton (1922) e do comitê da Associação Americana de Contabilidade de 1936, o foco consistia em apresentar um critério de mensuração (por exemplo, o custo histórico) e de alguns postulados (por exemplo, entidade, continuidade e periodicidade) (Liang, 2018).

Hendriksen e van Breda (2010) afirmam que, somente se "o contador puder visualizar a base na qual está se apoiando", evitará "aplicações incorretas e conclusões gerais errôneas". Para esse fim, Hendriksen e van Breda (2010) enumeraram seis postulados, junto a suas limitações:

1. a existência de entidade empresarial distinta - isso é universalmente presumido, muito embora seja, na realidade, apenas figura de linguagem;

2. a continuidade dessa entidade - a suposição de empresa em funcionamento é, em grande parte, questão de conveniência;

3. a equação do balanço - essa igualdade ocorre somente porque fechamos qualquer "buraco" que exista ajustando as contas de patrimônio dos acionistas;

4. o postulado monetário - essa é a premissa infundada de que "uma demonstração de ativos e passivos em dólares e cents é uma representação completa da posição financeira da empresa na data da demonstração" (Hendriksen e van Breda, 2010, p. 75); 
5. o postulado do custo - essa é a igualmente infundada premissa de que "o custo indica o valor verdadeiro para fins de demonstração inicial" (Hendriksen e van Breda, 2010, p. 75);

6. o postulado de reconhecimento de receitas - isso pressupõe que "a receita ou o lucro surgem repentinamente, de maneira integral, numa ocasião específica, geralmente a venda o que claramente não é verdade" (Hendriksen e van Breda, 2010, p. 75).

Paton (1922), a respeito do postulado da entidade, afirma que:

[a] suposição de uma entidade empresarial, um tanto separada e distinta das pessoas reais que conduzem suas operações, é uma concepção que tem sido grandemente deplorada por alguns escritores e firmemente defendida por outros. A empresa não é uma pessoa, portanto, falar disso como pessoa ou dotá-la de atributos pessoais é fazer uso de uma figura de linguagem. Mas isso não significa que a empresa particular não tenha uma existência real e mensurável. Uma empresa particular é uma instituição, não uma pessoa; mas uma instituição pode ser uma coisa muito real. Estamos todos vivendo no meio de um complexo sistema de instituições. (p. 473 )

A insatisfação com a orientação da teoria proprietária levou ao desenvolvimento da teoria da entidade. Seu arquiteto-chefe foi William Andrew Paton, professor de longa data na Universidade de Michigan, e, sob a teoria da entidade, a empresa e seus proprietários são seres separados. Os ativos pertencem à própria empresa; tanto o passivo como os detentores de capital são investidores nesses ativos com diferentes direitos e obrigações. A equação do balanço patrimonial é: " $\Sigma$ assets = $\sum$ equities (including liabilities)" (Wölk, Dodd e Tearney, 2004, p. 144).

Paton (1922) ressalta o caso da corporação, este postulado é validado do ponto de vista legal. A corporação é uma entidade real, dotada pelo Estado com todos os privilégios de qualquer pessoa de negócios. Pode adquirir títulos de propriedade, pedir dinheiro emprestado, participar de praticamente qualquer operação comercial reconhecida, contratar mão de 
obra, comprar e vender mercadorias e outros bens etc. Em geral, pode-se dizer que a corporação (não seus membros humanos) possui os ativos, dirige os negócios, empresta fundos, estabelece políticas de dividendos e assim por diante.

Leite Filho e Oliveira (2010) buscaram, na obra de Hendriksen e van Breda (1999, p. 75), informações sobre a pesquisa de Paton, como, por exemplo, "a existência de entidade empresarial distinta [...] é universalmente presumida, muito embora seja, na realidade, apenas figura de linguagem". Eles afirmam que há necessidade da existência da separação dos patrimônios de sócios e de empresas, mas admitem que, na prática, seja algo difícil de aplicar.

Na pesquisa de Azevedo (2010), com base na obra de Hendriksen e van Breda para extrair textos de Paton (1922), foi apresentada uma crítica ao posicionamento hierárquico dos Postulados e Princípios da Teoria Contábil, com o uso, por exemplo, dos conceitos de "entidade" e "continuidade".

Zeff (2013) afirma que Paton (1922) foi o defensor mais articulado da teoria da entidade, que ele chamou de "ponto de vista gerencial" em seu livro Teoria da Contabilidade (p. 52). Paton argumentou que, para a corporação, que ele chamou de "empresa de negócios por excelência" (Paton, 1922, p. 19, 45), acionistas comuns e preferenciais, também como detentores de títulos, assumiram riscos e suas ações se fundiram: todos eram fornecedores do capital. A pergunta que ele fez foi: "as contas e transações devem ser classificadas e analisadas do ponto de vista de toda a empresa como uma unidade operacional ou devem ser princípios contábeis que sejam apresentados em termos de um único interesse, o proprietário?” (Paton, 1922, p. 52). Seu "ponto de vista gerencial" concentrou-se no primeiro desses dois (Zeff, 2013).

A respeito do postulado da continuidade, Paton (1922) afirma que o contador não apenas assume a existência de uma entidade de negócios, mas ele também, como corolário, toma como certa a continuidade dessa entidade, isto é, ele supõe que o negócio com o qual está lidando é uma 
"continuidade". Essa segunda suposição dificilmente deve ser dita, pois é, em grande parte, uma mera conveniência. Ninguém está em posição de prever, com certeza, o futuro de um negócio específico. $O$ negócio é razoavelmente provável de continuar e de alguma forma não há garantia de sucesso no decorrer do tempo. Todo negócio envolve o elemento especulativo, embora, em alguns casos, seja muito mais pronunciado do que em outros.

Campos (2011) investigou as raízes epistemológicas do conceito da continuidade em Contabilidade, explicando seu significado e sua utilização. Foram demonstrados os significados de "axioma", "postulado" e "princípio", discorrendo-se sobre o papel desses termos na construção do conhecimento e como base na utilização do conceito de continuidade na Contabilidade. Também foi discutido o fundamento contábil do conceito da continuidade, no qual se identificou que grande parte das obras consultadas utiliza uma abordagem prescritiva para o tratamento do tema, como é o caso de textos emanados de órgãos reguladores da profissão contábil.

O "going concern", assim denominado na versão em inglês, é observado por Paton como inteiramente razoável, na ausência de evidência que dê uma clara presunção em contrário, pois é certamente justo supor que o negócio em particular vai continuar, pelo menos para o futuro próximo. O contador, portanto, tem o direito de tomar como certo que a preocupação específica na qual ele está interessado continuará a operar por algum tempo. Concebivelmente, a falência pode ocorrer, mas não precisa ser antecipada nas contas.

Na abordagem apresentada por Paton (1922), na equação do balanço: "o total das propriedades e o total das representações de propriedade, proprietários e outros elementos combinados - a suposição, em outras palavras, de que o total dos ativos de cada negócio é igual ao total dos passivos [...]" (p. 481)2.

2 "The total of the properties and the total of the representations of ownership, proprietary and other elements combined - the assumption, in other words, that the total of the assets of every business is equal to the total of the equities" (tradução livre). 
Há um pressuposto de que, em cada empresa, existe uma equação. Os ativos representam uma declaração direta do valor das propriedades da empresa; os passivos representam uma demonstração indireta dos mesmos valores. Em um caso, o contador está listando as propriedades objetivas; no outro, ele está registrando a distribuição adequada do total de ativos entre os vários indivíduos e interesses que têm reivindicações nele. Em um caso, a atenção está sendo focalizada nos objetos nos quais os fundos foram gastos; no outro, nas fontes desses fundos. O total das propriedades constitui o total da riqueza ou do capital da empresa; as ações expressam a dispersão desse capital entre os diversos investidores envolvidos. No que diz respeito aos ativos, o credor tem direito, no caso de liquidação, a qualquer saldo disponível após o cumprimento de todas as outras reivindicações. No caso de insolvência forçada, é provável que esse montante seja nulo ou insignificante e tenha pouca relação com os valores dos balanços anteriores. Além disso, os proprietários têm direito a uma participação em todo o excesso de lucros futuros da empresa, um direito que depende, para ser aplicado, da política específica do conselho de administração.

Paton mantém, em particular, no que diz respeito à equação do balanço, que a propriedade e os passivos são, na verdade, seções de uma divisão maior: passivos iguais a propriedades é a expressão mais lógica da condição financeira do negócio (Meyer, 1973).

Na visão de Paton, no caso dos passivos, os montantes atribuídos pelo contador provavelmente serão um pouco mais razoáveis. Em geral - ignorando descontos não acumulados, prêmios não amortizados etc. pode-se dizer que o contador considera a soma devida no vencimento como o verdadeiro passivo. Na ausência de insolvência, esta é a quantia que finalmente será realizada pelo investidor contratual, e é provável que aproxime o princípio original, caso a empresa vá à falência, já que existe ainda alguma possibilidade de os credores receberem montantes. Consequentemente, existe um grande elemento de precisão factual nos números do balanço que estão anexados às ações contratuais. Mesmo aqui, 
claro, o valor de mercado de uma determinada ligação ou outra garantia semelhante pode variar visivelmente do montante que aparece na empresa emissora da demonstração financeira.

Postulado monetário, também denominado "condição financeira e balanço", está relacionado à situação financeira de uma empresa, de acordo com Paton, e pode ser apresentado no que diz respeito a ativos e passivos; ou seja, ele assume que uma demonstração de ativos e passivos em moeda corrente é uma representação completa da condição financeira da empresa na data da declaração. O balanço, como uma declaração verdadeira da condição financeira, não deve ser levado muito a sério, pois tem limitações bem definidas nas circunstâncias mais favoráveis. Uma demonstração do balanço de valores de ativos é realmente apenas provisória, visto que depende do futuro para sua validação.

O balanço de uma empresa grande e complexa tende a ser, naturalmente, imperfeito por várias razões de ordem técnica. A tomada de inventário, por exemplo, pode consumir várias semanas, e o valor final colocado no balanço não será mais do que uma aproximação do valor das mercadorias na banda na data precisa da declaração. Isto é, se existem potenciais ativos ou potenciais passivos na situação, que estão suficientemente à vista para serem mais do que simples possibilidades, considera-se boa prática indicar esses elementos, de alguma forma suplementar, em conexão com o balanço patrimonial (Paton, 1922).

Paton (1922), ao enfocar a questão do postulado do custo, faz algumas suposições importantes relacionadas ao cálculo de custos e à avaliação. Em primeiro lugar, ele assume que o custo dá valor real para fins de declaração inicial, sendo uma das premissas mais importantes subjacentes à Contabilidade na prática, na medida em que é o único fato definitivo disponível quando uma propriedade é comprada, construída ou adquirida de outra forma. É inteiramente razoável, portanto, que seja cobrada, em qualquer caso, a conta de ativo apropriada com o valor desse custo, já que ele enfatiza que o contador não deve tentar determinar o valor de venda, mas o valor de custo. Eis que surge, então, a pergunta: quais os custos desse 
empreendimento em particular? Nesse caso, deve o contador relatar os custos reais, qualquer que seja o valor.

Paton (1922), analisando o postulado de reconhecimento de receitas, assume que as despesas se acumulam, mas destaca que essa receita líquida ou lucro aparece repentinamente, em alguma ocasião específica, geralmente a da venda. Isso significa que a "despesa" do contador para o negócio em particular e o "custo de produção" do economista são duas coisas bem diferentes. $\mathrm{O}$ economista está falando sobre o custo determinante do preço, $\mathrm{O}$ custo para o comprador; portanto, assume que a receita líquida de negócios, pelo menos em parte, é um custo essencial de produção, um elemento que o preço deve cobrir se a produção continuar em volume satisfatório.

Podemos observar que, em vários momentos, Paton utiliza seu conhecimento em Economia para explicar fenômenos que ocorrem na Contabilidade, o que contribui imensamente para um perfeito entendimento das questões contábeis em foco. Alguns autores, ao citar os postulados de Paton (1922), não incluem a sequência como um dos postulados, embora ele dê uma especial atenção a esse tema. Analisando essa questão, observamos que, em vários pontos, o contador considera necessário adotar certas premissas com respeito a sequências de dados e a relações entre séries de fatos. Ele normalmente considera como certo que uma perda no valor do ativo recaia sobre ou extinga a mais recente propriedade acumulada. Assim, os vencimentos são normalmente cobrados, em primeiro lugar, contra o lucro bruto ou o lucro líquido do período e, em segundo lugar, são deduzidos dos lucros acumulados, cobrados das contas e mostrado o investimento original apenas como último recurso.

Ele destaca que a Contabilidade passou por grandes avanços e é altamente desejável, no decurso desse rápido desenvolvimento, que os pilares da teoria e da prática sejam ocasionalmente examinados e analisados, com vistas a descobrir, com precisão, com que firmeza eles estão ancorados.

Esse trabalho desenvolvido por Paton reuniu diversos conceitos visionários a respeito da Contabilidade que até hoje estão sendo aplicados. Como 
destaca Zeff (2013), Paton argumentou que a declaração de renda deveria ser elaborada para mostrar uma receita líquida, resultando em todas as ações dos ativos. Esta é uma posição similar às que foram tomadas nos últimos anos por muitos que afirmam que o objetivo do relatório financeiro é fornecer informações contábeis aos investidores em títulos de dívida e ações. Paton, ao propor que os dados contábeis da empresa fossem relatados a todos os fornecedores de capital com rendimento, argumentou que as taxas de juros devem ser como uma distribuição do lucro líquido, não como uma despesa para se chegar ao lucro líquido. O interesse é, afinal, a renda aos credores (cap. XI). Hoje, praticamente ninguém afirma que as taxas de juros devam ser mostradas na demonstração de resultados, como outra que não seja uma despesa.

A posição de Paton, no entanto, élogicamente defensável se levarmos em conta que o lucro líquido deve ser definido por referência aos investidores em títulos de dívida e ações. Além disso, ele também considerava o governo como uma parte interessada, apontando "Imposto Federal e Imposto sobre Lucros” como distribuição do lucro líquido (Paton, 1922, p. 269).

\section{Procedimentos metodológicos}

O objetivo proposto classifica a pesquisa como uma pesquisa exploratória, sendo realizada em área na qual há pouco ou nenhum conhecimento anterior em que possamos buscar informações sobre o problema (Collis e Hussey, 2005).

A pesquisa exploratória foi realizada com base em fontes diversas: Google Acadêmico, livros, artigos, teses e dissertações. Realizou-se um estudo exploratório descritivo, com o objetivo de identificar e obter informações sobre as características de um determinado problema ou questão (Collis e Hussey, 2005).

Para fazer a análise de tipologias de citações, utilizamos o método empregado por Oppenheim e Renn (1978). Embora haja vários métodos 
para classificar as relações entre citações e artigos citados, optamos em empregar essa tipologia por apresentar, de forma detalhada, a classificação que considera os sete motivos - também descritos como categorias - que levam um autor a citar outro trabalho: a) relatar um trabalho histórico; b) descrever outro trabalho relevante; c) fornecer informações ou dados, exceto para comparação; d) fornecer informações ou dados para comparação; e) utilizar equação teórica; f) reproduzir a metodologia; g) rejeitar teoria ou método não aplicável ou não recomendado.

\section{Análise e resultados}

Oppenheim e Renn (1978) desenvolveram uma nova tipologia de citações que acreditavam ser mais fácil de usar e compreender. Assim, realizaram um estudo para descrever e averiguar por que artigos antigos ainda são citados muitos anos depois de serem publicados. Verificou-se que cerca de $40 \%$ das citações foram por razões históricas, mas que, nos restantes $60 \%$ dos casos, o papel antigo ainda é usado ativamente.

Quanto aos sete motivos/categorias que levam um autor a citar outro trabalho, a primeira categoria foi utilizada quando os artigos foram citados por fatores históricos, na medida em que os respectivos autores foram homenageados por terem sido os pioneiros no trabalho de campo em questão. Já nos momentos em que o trabalho utilizado como referência foi considerado relevante (teoria ou equação), seja pela importância conceitual, seja porque o autor simplesmente concorda com a citação, o enquadramento recaiu na categoria B, tendo em vista as informações importantes que são descritas ou discutidas (mas não simplesmente referidas) pelo autor.

A categoria c cobriu os casos em que o autor fez uso específico da citação quando o intuito não era comparar; enquanto o uso de um artigo citado para obter informações que foram usadas para comparação foi classificado como pertencente à categoria $\mathrm{D}$. $\mathrm{O}$ critério de classificação referente à categoria E foi utilizado para delimitar todos os casos em que o artigo realmente empregou a equação teórica citada para fins de cálculo. 
A categoria $\mathrm{F}$ contemplou os casos de artigos que citaram um determinado autor por terem sido utilizadas técnicas, práticas ou teóricas desenvolvidas por ele, em determinado artigo; ou seja, quando um método era usado para resolver uma equação desenvolvida pelo trabalho de citação, e o método foi dado no artigo citado. Desse modo, se foi usada uma equação para obter dados, definimos como E, mas, se citar a equação em si, enquadra-se na opção F.

Se um autor sentiu que era necessário afirmar que a teoria ou o método não era aplicável, ou não era a melhor opção para atender ao seu propósito, esse caso foi alocado na categoria G. Um trabalho que cita a mesma obra mais de uma vez e pelo mesmo motivo dado na tipologia foi enquadrado na categoria particular uma vez. Por sua vez, quando um artigo é citado na introdução de um trabalho, como exemplo de produção anterior no campo (categoria A), mas, em seguida, é citado novamente por motivo distinto, a classificação se dá em função do uso feito dele, e não pelo papel histórico desempenhado.

O conceito de "histórico" para os autores está associado à ideia de evidenciar a primeira pessoa a trabalhar no campo, homenagens aos pioneiros ou se um artigo foi citado porque descreveu trabalho anterior. Nas citações realizadas a partir da obra de Paton (1922), identificamos a presença de quase todos os motivos destacados por Oppenheim e Renn.

Ao realizarmos uma breve pesquisa no Google Academic ("Paton, 1922, Paton"), identificamos 178 trabalhos que citam essa obra. A mesma pesquisa com a utilização de "Paton, 1922 apud", entretanto, obteve um resultado bem maior. Identificamos, constantemente, nos periódicos voltados para a Contabilidade, artigos que contêm citações indiretas com o uso de apud, o que deixa explícito, de forma patente, a notória subutilização dessa obra por um grande número de pesquisadores.

O uso da preposição latina apud não é muito aconselhável em uma pesquisa científica, pois sua utilização excessiva pode sinalizar um esforço reduzido do autor em busca do texto original, visto que utiliza uma 
terceira pesquisa para extrair o material por vezes inacessível. Para Magtaz e Berlinck (2010), apud trata-se de um recurso que deve ser utilizado com muita parcimônia e depois de um genuíno esforço de pesquisa da citação direta. A suposta inacessibilidade do texto citado é sempre relativa, já que a pesquisa foi citada por outro autor e este teve acesso ao trabalho.

Excetuando os casos em que é impossível o acesso ao texto original, seja por deterioração da mídia, seja pela inacessibilidade do texto, deve-se evitar a todo custo a referenciação indireta ( $a p u d)$. Um excerto tomado fora de seu contexto pode dar margem a interpretações equivocadas, o que pode gerar falsidade sobre o que realmente o autor está dizendo. Portanto, faz-se necessário o conhecimento do texto original que se pretende citar a todos que se propõem à produção de textos acadêmicos, a fim de dar maior credibilidade à sua produção bibliográfica. Tanto editores quanto consultores de revistas científicas devem coibir esse recurso e estimular os autores a busca e leitura de textos de fontes primárias (Magtaz e Berlinck, 2010).

O excesso de uso de apud impede que a obra possa ser analisada na plenitude de seus muitos ângulos e discernimentos possíveis. Diante desse contexto, entende-se que é importante ler, consultar e explorar os ensinamentos de Paton diretamente na sua obra original, pois esse trabalho trouxe grandes contribuições para a construção da teoria da Contabilidade, e sua subutilização inviabiliza o entendimento da importância dele nos estudos contábeis.

Como avançaremos na pesquisa científica na área contábil se realizarmos, de forma recorrente, apenas a citação da citação? É imperioso que trilhemos novas searas e encaremos os estudos acadêmicos sob novas perspectivas, pois muitos terrenos ainda precisam ser descobertos e garimpados.

As citações não são somente históricas ou formas de descrição de outro trabalho relevante. Podemos observar, na citação de Barker e McGeachin (2013), que, em geral, passivos e ativos que não forem atributo de medição de valor de saída, uma suposição típica implícita é a de uma troca de igual valor. Essa suposição permite que um valor de entrada observável possa 
ser usado como um proxy para um valor de saída: o valor de saída (desconhecido) do ativo ou passivo é definido como igual ao valor de entrada (conhecido) do lado correspondente da dupla entrada. Essa abordagem de medição indireta de proxy pode ser argumentada para fornecer a lógica predominante da Contabilidade de custos (Paton, 1922; Sterling, 1970) Neste caso, Barker e McGeachin (2013) citaram Paton (1922) e Sterling (1970) sem a utilização de apud.

O caso inverso ao dado acima pode ser verdadeiro também: o exemplo de um ativo gerado por algumas remunerações baseadas em ações ilustra o caso de uma saída de valor que é observável com um valor de entrada que não é observável. Fuji e Slomski (2003) apresentaram, por exemplo:

A ideia de a Contabilidade orientar-se para o usuário fora mencionada, por exemplo, por Paton (1922, p. 16): a função da Contabilidade e das explicações de princípios e procedimentos contábeis deve ser exposta em termos de necessidades e das finalidades dos proprietários. (p. 34)

Há muito tempo existe apoio na literatura para uma categoria de financiamento separada. Paton (1922) defendeu a colocação de imposto de renda e custo de juros "abaixo da linha" na demonstração de resultados. Ele argumentou que a receita (como ele chamou) deve ser um retorno a todos os fornecedores de capital, e os juros eram, portanto, a distribuição dessa receita líquida a uma classe de capital de fornecedores (Barker, 2010).

A tese, mesmo tendo sido escrita há quase um século, mantém-se viva e atual. Nos trechos nos quais Barker citou Paton (1922), as citações não o abordam por uma obra histórica que apenas pode ser citada para prestar uma homenagem ao autor. Ele trouxe citações de Paton para fortalecer uma ideia ou posicionamento.

Nesse ponto, é feita a análise das obras que citaram Paton (1922), de acordo com a tipologia de Oppenheim e Renn (1978). No levantamento 
Paton") e apresentado na Tabela 1, identificamos 178 trabalhos que citam essa obra. Entretanto, 68 citações não estavam enquadradas como artigo, livro, dissertação/tese ou não foi possível realizar download.

Tabela 1. Tipologia das citações

\begin{tabular}{c|c|c|c|c}
\hline \multirow{2}{*}{ Tipologia } & \multicolumn{3}{|c|}{ Citações de Paton (1922) } & \multirow{2}{*}{ Totais } \\
\cline { 2 - 4 } & Artigo & Livro & $\begin{array}{c}\text { Dissertação/ } \\
\text { tese }\end{array}$ & \\
\hline A & 8 & 7 & 1 & 16 \\
\hline B & 13 & 3 & 2 & 18 \\
\hline C & 56 & 9 & 6 & 71 \\
\hline D & 1 & 2 & - & 3 \\
\hline \multirow{2}{*}{ E } & - & - & - & - \\
\hline \multirow{2}{*}{ F } & 2 & - & - & 2 \\
\hline \multirow{2}{*}{ G } & - & - & - & 110 \\
\hline \multirow{2}{*}{} & 80 & 21 & 9 & \\
\cline { 2 - 5 } & & & & \\
\hline
\end{tabular}

Fonte: elaboração própria.

Na verdade, a maioria das citações efetuadas se deu com base na tipologia c, fato constatado em todas as três divisões: artigo, livro e dissertação/tese.

Os livros, como já dito, priorizaram a adoção da tipologia c, mas se pôde observar um grande volume de trabalhos que utilizaram a bibliografia de Paton (1922) essencialmente com fins históricos (tipologia A), simplesmente para prestar homenagem, e não se aprofundaram no texto citado.

A partir da análise efetuada, observou-se que nenhum autor fez citação na perspectiva da tipologia $\mathrm{G}$, na qual o autor sentiu que era necessário afirmar que certa teoria ou método não era aplicável para atingir determinado propósito. 
Oppenheim e Renn (1978) observaram, em seus cálculos, que, em cada artigo citado, é referido, em média, 1,05-1,15 vezes ao longo de cada artigo que o cita, e que essa regra tem validade geral. Cerca de $40 \%$ das citações foram por razões históricas; contudo, nos restantes $60 \%$ dos casos, o papel antigo ainda é usado ativamente. Logo, o fator histórico não é o principal motivo de quem busca respostas para seus problemas de pesquisa no trabalho de Paton.

Apesar de encontrarmos diversos trabalhos que citassem Paton (1922), poucos são os autores que constantemente estão desenvolvendo pesquisas sobre o tema.

Na Tabela 2, pode-se identificar os autores que mais citaram o trabalho de Paton (1922), entre as 110 pesquisas da amostra.

Tabela 2. Principais autores

\begin{tabular}{c|l|c}
\hline \multicolumn{2}{c|}{ Autores que mais citaram } & Quantidade \\
\hline 1 & Stephen Addam Zeff & 8 \\
\hline 2 & Richard Barker & 4 \\
\hline 3 & Richard Mattessich & 3 \\
\hline
\end{tabular}

Fonte: elaboração própria.

A maioria das citações foi por meio de artigo (72 \%), logo de livros (21 \%) e teses/dissertações (9\%). A partir da amostra, identificamos que, no ano de 2015, houve o maior número de citação da monografia de Paton (1922).

A Tabela 3 mostra que a maioria dos trabalhos foi escrita por um único autor, ou seja, não identificamos a tendência de formação de redes de pesquisadores que explorassem o tema. Os três autores que mais citaram Paton (1922) são homens. Entretanto, dois dos trabalhos desenvolvidos por Richard Barker tiveram a participação de Anne McGeachin. 
Tabela 3. Autoria

\begin{tabular}{c|l|c|c|c}
\hline \multicolumn{2}{c|}{ Autores } & $\begin{array}{c}\text { Único } \\
\text { autor }\end{array}$ & $\begin{array}{c}\text { Com } \\
\text { coautoria }\end{array}$ & Total \\
\hline 1 & Stephen Addam Zeff & 7 & 1 & 8 \\
\hline 2 & Richard Barker & 2 & 2 & 4 \\
\hline 3 & Richard Mattessich & 2 & 1 & 3 \\
\hline
\end{tabular}

Fonte: elaboração própria.

Podemos observar que, apesar de Paton pertencer à Escola NorteAmericana, seu trabalho não ficou limitado aos Estados Unidos. Na Tabela 4, identificamos citações da tese de Paton que ultrapassaram fronteiras continentais.

Tabela 4. Centros acadêmicos

\begin{tabular}{c|l|l|l|l}
\hline \multicolumn{2}{c|}{ Autores } & \multicolumn{1}{c|}{ Universidade } & Localidade & \multicolumn{1}{c}{ País } \\
\hline 1 & Stephen Addam Zeff & $\begin{array}{l}\text { Jesse H. Jones } \\
\text { Graduate School of } \\
\text { Management, Rice } \\
\text { University }\end{array}$ & Houston & Estados Unidos \\
\hline 2 & Richard Barker & Oxford University & Oxford & Reino Unido \\
\hline 3 & Richard Mattessich & $\begin{array}{l}\text { University of British } \\
\text { Columbia }\end{array}$ & Vancouver & Canadá \\
\hline
\end{tabular}

Fonte: elaboração própria. 
Tabela 5. Formação dos autores

\begin{tabular}{c|l|l|l|l}
\hline \multicolumn{2}{c|}{ Autores que mais citaram } & Graduação & \multicolumn{1}{|c|}{ Mestrado } & Doutorado \\
\hline 1 & Stephen Addam Zeff & $\begin{array}{l}\text { Universidade } \\
\text { do Colorado }\end{array}$ & $\begin{array}{l}\text { Universidade do } \\
\text { Colorado }\end{array}$ & $\begin{array}{l}\text { Universidade } \\
\text { de Michigan }\end{array}$ \\
\hline 2 & Richard Barker & $\begin{array}{l}\text { Universidade } \\
\text { de Oxford }\end{array}$ & $\begin{array}{l}\text { Universidade de } \\
\text { Cambridge }\end{array}$ & $\begin{array}{l}\text { Universidade } \\
\text { de Cambridge }\end{array}$ \\
\hline 3 & Richard Mattessich & $\begin{array}{l}\text { Faculdade de } \\
\text { Engenharia } \\
\text { de Viena }\end{array}$ & $\begin{array}{l}\text { Escola de Economia } \\
\text { e Administração de } \\
\text { Empresas de Viena } \\
\text { (MBA) }\end{array}$ & $\begin{array}{l}\text { Universidade } \\
\text { de Economia } \\
\text { de Viena }\end{array}$ \\
\hline
\end{tabular}

* Zeff ainda é doutor em Economia honoris causa, Turun kauppakorkeakoulu (Escola Turku de Economia e Administração de Empresas); doutor em Letras honoris causa, Universidade de Waterloo; doutor em Ciências Econômicas e Administrativas honoris causa, Universidade de Alcalá.

** Assim como Zeff, Richard Mattessich também recebeu títulos de doutor honorário na Universidade de Madri (Complutense) em 1998; na Universidade de Málaga, na Espanha, em 2006; na Universidade de Montesquieu, na França, em 2006, e na Universidade de Graz, na Áustria, em 2007.

Fonte: elaboração própria.

\section{Conclusão}

A Escola de Pensamento Contábil, da qual Paton fez parte, teve origem em entidades ligadas a profissionais da área contábil com a constante preocupação com a qualidade e padronização das informações contidas nas demonstrações contábeis. Este trabalho retrata bem o contexto socioeconômico e político vivido na época da sua escrita. Os conceitos estudados foram de grande importância para os profissionais daquela época. A Contabilidade tem o encargo de acompanhar e discutir as possíveis mudanças e adaptações necessárias para melhores práticas.

A tese de Paton explorou, aperfeiçoou e agregou conceitos desenvolvidos por outros autores de forma a apresentar os primeiros passos para a 
construção de uma teoria contábil. Os ensinamentos desse trabalho devem ser transmitidos para os futuros contadores, pois muitos dos seus apontamentos continuam sendo aplicados e desenvolvidos na Contabilidade.

O trabalho desenvolvido por Paton em 1922 trouxe inúmeras contribuições para a teoria da Contabilidade e para o ensino da Contabilidade como um todo. Observamos, entretanto, que alguns autores ainda relutam em consultar e explorar as fontes primárias da pesquisa e preferem citá-lo por intermédio de terceiros.

Para fazer a análise de tipologias de citações, utilizamos o método empregado por Oppenheim e Renn (1978); assim, pudemos observar que a maioria das citações foi classificada na tipologia c. Logo, a tese de Paton não é apenas um trabalho histórico, pois a sua citação ainda traz fundamentação para conceitos vigentes. $O$ resultado da análise das citações feitas em relação à obra de 1922 está de acordo com os achados de Oppenheim e Renn.

As principais contribuições da obra de Paton (1922) consistem na busca, na prática contábil e na formação da teoria, visto que delineou alguns conceitos, como "custo corrente", discussão sobre o goodwill e os postulados. Estes últimos foram um grande avanço para a adaptação dos princípios de Contabilidade propriamente ditos, assim como o princípio de entidade e continuidade, também muito discutido nos debates atuais. E, mesmo de forma embrionária, essa tese traz uma contribuição para a ideia de mensuração e uma introdução ao conceito de custo corrente.

Paton se dedicou ao ensino de Contabilidade e foi um participante ativo de todas as principais organizações profissionais de Contabilidade da época. O seu trabalho trouxe relevantes contribuições para a teoria e prática contábil. Dessa forma, a estreita relação entre os profissionais contábeis em exercício e os professores de Contabilidade resultou em avanços significativos das Ciências Contábeis da época.

Infelizmente, o ensino da história da Contabilidade está sendo visto de forma isolada do contexto atual. Torna-se necessária, portanto, uma busca 
no passado, baseada em um maior estudo e aprofundamento das obras históricas, para que identifiquemos as contribuições de autores clássicos que permanecem atuais nos seus relatos.

\section{Referências}

Azevedo, R. F. L. (2010). Entidade e continuidade: reflexões sobre a base conceitual e a estrutura hierárquica dos Postulados e Princípios da Contabilidade. Revista Contemporânea de Contabilidade, 7(14), 137-158.

Barker, R. (2010). The operating-financing distinction in financial reporting. Accounting and Business Research, 40(4), 391-403.

Barker, R. e McGeachin, A. (2011). The recognition and measurement of liabilities in IFRs. https://papers.ssrn.com/sol3/papers.cfm?abstract_id=1952739

Barker, R. e McGeachin, A. (2013). Why is there inconsistency in accounting for liabilities in IFRS? An analysis of recognition, measurement, estimation and conservatism. Accounting and Business Research, 43(6), 579-604.

Campos, G. M. (2011). Raízes epistemológicas da continuidade em contabilidade. Enfoque: Reflexão Contábil, 30(3), 20-32.

Collis, J. e Hussey, R. (2005). Pesquisa em administração: um guia prático para alunos de graduação e pós-graduação. Porto Alegre: Bookman.

Cooper, J. (2007). Debating accounting principles and policies: The case of goodwill, 1880-1921. Accounting, Business \& Financial History, 17(2), 241-264.

D’Alvise, P. (1934). Principii e precetti di ragioneria per lamministrazione economica delle aziende. Padova: Cedam.

Fuji, A. H. e Slomski, V. (2003). Subjetivismo responsável: necessidade ou ousadia no estudo da contabilidade. Revista Contabilidade \& Finanças, 14(33), 33-44.

Harris, W. (1884). Goodwill. The Accountant, 10(1), 9-14.

Hendriksen, E. S. e van Breda, M. F. (1999). Teoria da contabilidade. São Paulo: Atlas.

Hendriksen, E. S. e van Breda, M. F. (2010). Teoria da contabilidade. São Paulo: Atlas.

Iudícibus, S. e Martins, E. A. (2015). Estudando e pesquisando teoria: O futuro chegou? Revista Universo Contábil, 11(1), 6-24.

Leite Filho, G. A. e de Oliveira, L. L. (2010). Os motivos que influenciam a não aplicação do princípio da entidade pelos empresários do ramo de autopeças da cidade de Montes Claros-MG. Enfoque: Reflexão Contábil, 29(1), 49-61. 
Liang, P. J. (2018). A review of Nohora García’s “understanding Mattessich and Ijiri: A study of accounting thought". De Computis-Revista Española de Historia de la Contabilidad, 15(1), 101-111.

MacNeal, K. (1939). Truth in accounting. Philadelphia: University of Pennsylvania. Magtaz, A. C. e Berlinck, M. T. (2010). Apud. Revista Latinoamericana de Psicopatologia Fundamental, 13(1), 13-15. http://dx.doi.org/10.1590/S141547142010000100001

Meyer, P. E. (1973). The accounting entity. Abacus, 9(2), 116-126.

Oppenheim, C. e Renn, S. P. (1978). Highly cited old papers and the reasons why they continue to be cited. Journal of the American Society for Information Science, 29(5), 225-231.

Paton, W. A. (1918). The significance and treatment of appreciation in the accounts. Ann Arbor, EuA.: Michigan Academy of Science, Twentieth Annual Report, University of Michigan.

Paton, W. A. (1922). Accounting theory, with special reference to the corporate enterprise. New York: Ronald Press.

Santos, J. L. D., Schmidt, P., Pinheiro, P. R. e Nunes, M. S. (2006). Fundamentos de contabilidade de custos. São Paulo: Atlas.

Schmidt, F. (1921). Die organische Bilanz im Rahmen der Wirtschaft. Leipzig: G. A. Gloeckner

Schmidt, P. (2000). História do Pensamento Contábil (History of Accounting Ideas). Porto Alegre, Bookman.

Soares, S. V. e Vicente, E. F. R. (2014). Bibliografia brasileira sobre teoria da contabilidade: o que se encontra nos livros? Práticas em Contabilidade e Gestão, 2(1), 31-61.

Sterling, R. (1970). Theory of the Measurement of Enterprise Income. Lawrence: University of Kansas Press.

Sweeney, H. W. (1932). Stabilized Appreciation. The Accounting Review, 7(2), 115-121.

Williams, K. L. e Lawrence, H. J. (2018). William A. Paton: A Study of His Accounting Thought. London: Emerald Publishing Limited.

Zeff, S. A. (1999a). The evolution of the conceptual framework for business enterprises in the United States. Accounting Historians Journal, 26(2), 89-131. 
Zeff, S. A. (1999b). La evolución del marco conceptual para las empresas mercantiles en Estados Unidos. Revista Española de Financiación y Contabilidad, 100, 151-194.

Zeff, S. A. (2013). The objectives of financial reporting: A historical survey and analysis. Accounting and Business Research, 43(4), 262-327.

Zeff, S. A. (2016). John B. Canning: A view of his academic career. Em S. A. Zeff (Ed.), Memorial Articles for $20^{\text {th }}$ Century American Accounting Leaders (pp. 72-113). New York/London: Routledge.

Wölk, H., Dodd, J. e Tearney, M. (2004). Accounting Theory. Conceptual Issues in a Political and Economic Environment. Norwalk, Connecticut: Thomson, South-Western College Publishing. 